Paidéia, 2006, 16(34), 241-252

\title{
SIGNIFICAÇÕES DE PATERNIDADE ADOTIVA: UM ESTUDO DE CASO ${ }^{1}$
}

\author{
Raylla Pereira de Andrade ${ }^{2}$ \\ Nina Rosa do Amaral Costa \\ Maria Clotilde Rossetti-Ferreira \\ Universidade de São Paulo- FFCLRP
}

\begin{abstract}
Resumo: Movimentos sociais do final do século XX questionaram a distribuição de papéis nos múltiplos arranjos familiares e favoreceram maior participação paterna nos cuidados infantis. Adotar é uma possibilidade de tornar-se pai. O objetivo desta pesquisa foi investigar significações de paternidade no processo de adoção de um bebê. Usou-se a perspectiva da Rede de Significações em interlocução com estudos sobre adoção, gênero e família. Seis entrevistas realizadas com dois homens casados adotantes de bebês foram lidas exaustivamente, sendo estabelecidos eixos de significação organizadores do corpus. A análise mostra que esses pais significam o filho como sua "continuidade" no mundo e decorrência "natural" do casamento. Ambos supervalorizam sua função de provedor e se posicionam como "ajudantes" da mãe nos cuidados infantis. A adoção aparece como solução à infertilidade. A revelação é tida como necessária, porém difícil. Esses pais se dizem satisfeitos com o papel parental, mostrando paternidades multifacetadas e constantemente negociadas.
\end{abstract}

Palavras-chave: paternidade; adoção; rede de significações; família.

\section{MEANINGS OF ADOPTIVE FATHERHOOD: A CASE STUDY}

Abstract: Late twentieth century social movements questioned the distribution of roles in the family, and favored a wider father participation in child care. To adopt is a possibility of becoming a father. This study aimed to investigate the meanings about fatherhood which emerge in the process of adopting a baby. The network of meanings theoretical-methodological perspective was used, together with studies on adoption, gender and family. Six interviews made with two married men who adopted babies were thoroughly read to establish some relevant meanings which emerged from the corpus. The analysis showed that those fathers meant the child as a "continuity" of themselves and as a "natural" consequence of marriage. Both emphasized their function as resources providers and positioned themselves as mother's "helpers" in the care for their child. The adoption appears as a solution for infertility. Revelation is considered necessary, but difficult. Those fathers are happy with their role.

Key words: fatherhood; adoption; network of meanings; family.

\section{Introdução}

\section{Repensando a Paternidade: Velhos e Novos Conceitos}

Partindo da premissa de que uma paternidade (adotiva ou não) é construída em relação aos discursos e práticas sociais de sua época, propos-se uma reflexão sobre velhos e novos conceitos relativos às

\footnotetext{
${ }^{1}$ Recebido em 14/10/05 e aceito para publicação em 19/10/06.

${ }^{2}$ Endereço para correspondência: Raylla Pereira de Andrade, Departamento de Psicologia e Educação. Centro de Investigações sobre Desenvolvimento Humano e Educação Infantil (CINDEDI). Avenida Bandeirantes, 3900, CEP: 14040-901, Ribeirão Preto-SP, E-mail: rayllandrade@yahoo.com.br
}

formas de organização familiar e vivências de paternidade.

A partir das transformações sócio-econômicas do século XVIII (surgimento da sociedade industrial), tornou-se emergente o arranjo familiar composto por pai, mãe e fillhos, a chamada família nuclear moderna ou conjugal. Em um movimento de cisão entre público e privado relacionado a esse modelo de família, ganha corpo uma concepção de amor materno em que a mãe passa a ser significada como a mulher abnegada que deve se dedicar inteiramente à educação e cuidado dos filhos, ficando restrita ao âmbito doméstico. Por sua vez, o homem é remetido ao es- 
paço público, ao mundo do trabalho, político e social, dentro de um modelo de relações patriarcais de gênero, com a função primordial de ser o pai, provedor e chefe de família (Áries, 1981; Fonseca, 1995; Costa, 2005).

Badinter (1985) lembra que nas famílias marcadas pelo patriarcado a criança tornava-se propriedade exclusiva da mãe, desenrolando-se o início da vida em um quase-desconhecimento do pai. A autora também desconstrói a idéia do amor materno enquanto instinto (universal e natural), e defende que ele é um mito construído sócio-historicamente.

Lewis e Dessen (1999) mostram que diferentes fatores podem interferir no envolvimento paternal e maternal, sendo que os modelos fundamentados na biologia (o homem biologicamente despreparado para os cuidados infantis) e na personalidade do indivíduo (tal pai é participativo porque é característica dele gostar de cuidar de criança) eram mais característicos das décadas de 70 e 80 . Nos anos 90 , cresceu a perspectiva que explica o envolvimento paternal como conseqüência de fatores sociais, em especial, a divisão de trabalho doméstico de casais em que ambos trabalham fora de casa.

Vale ressaltar que a própria Psicologia do Desenvolvimento, por muito tempo (décadas de 60 e 70), privilegiou os estudos focados na díade mãe-criança, praticamente excluindo o pai das relações parentais e do processo de desenvolvimento infantil (Rodrigues \& Trindade, 1999).

Entretanto, movimentos sociais do final do século XX (o feminista, gay e estudantil) e as transformações econômicas (entrada maciça de mulheres no mercado de trabalho) contribuíram para o questionamento das diferenças de gênero e favoreceram argumentações em prol de maior participação paterna nos cuidados infantis (Arilha, Medrado \& Ridenti, 1998). Assim, paralelamente ao modelo tradicional de papéis parentais, baseado na autoridade paterna e na responsabilidade materna no cuidado com os filhos, fala-se no surgimento do chamado "novo pai" (Trindade \& Menandro, 2002; Hennigen \& Guareschi, 2002), ou "pai andrógino"(LaRossa, 1988) ou presente num "casal igualitário" (Salém, 1989).

Salém (1989) e Badinter (1993) trazem descrições semelhantes deste novo pai. Um homem oriun- do da camada média ou alta das grandes cidades, com nível de escolaridade e renda mais alto que a média, e com acesso às informações, inclusive às teorias psicanalíticas e pedagógicas. Tal pai deseja romper com o modelo de sua família de origem, demonstra mais as emoções e, em geral, vive com uma mulher também inserida no mercado de trabalho que não pretende ser mãe em tempo integral. Além disso, ele desempenha mais tarefas de cuidado e educação de filhos, relatam maior satisfação na relação conjugal e vivência da paternidade.

Sheehy (1997) também cita pesquisas mostrando que ter sucesso como pai dedicado e colaborador na tarefa de cuidar dos filhos faz bem à saúde física e mental do homem, além de ter um efeito importante sobre o bem-estar emocional dos filhos. Esses "pais reinventados" querem ser encarados como pessoas amáveis, confiáveis, e não como educadores morais distantes, chefes de família ou apenas provedores.

Para Gomes e Resende (2004), o pai contemporâneo, ao não se identificar com um mero reprodutor ou provedor econômico, faz-se presente na estrutura e dinâmica do contexto familiar. Assim, dispõe-se a redefinir seu papel, a vivenciar a paternidade e construir sua subjetividade como pai, instrumentalizandose para enfrentar novas demandas.

Entretanto, estudos brasileiros (Gomes \& Resende, 2004; Unbenhaum, 2000; Jablonski, 1998; Quadros, 1996; Salém, 1989) e americanos (Atkinson \& Blackwelder, 1993; LaRossa, 1988) discutem a assincronia existente entre cultura/ideologia e conduta/prática da paternidade. Para os autores, a despeito da ideologia de uma paternidade mais participativa nos cuidados infantis, no que se refere às práticas cotidianas, as mulheres continuam sendo as principais cuidadoras (Bustamante \& Trad, 2005). Essa ambivalência entre a moderna cultura da paternidade e a tradicional acaba aumentando os conflitos entre os casais na divisão dos cuidados infantis e pode gerar culpa naqueles pais, que vêem a distância entre o que fazem e o que deles é esperado. This (1987) reforça essa reflexão, e mostra a tendência social de promoção de um imaginário sobre o "bom pai", como figura ideal longe do pai "real".

Diante dessas transformações sociais nas formas de vivenciar a paternidade e do aumento dos 
questionamentos em relação ao papel do pai, interessou investigar os sentidos de paternidade no momento em que alguns homens se tornam pais pela primeira vez, por meio da adoção de um bebê. Assim, a pesquisa caracteriza-se no contexto de paternidade adotiva.

\section{Paternidade no contexto da adoção}

Em diferentes tempos históricos encontra-se registro de pais que, por diversas razões, abandonaram ou entregaram seus filhos para outras pessoas cuidarem, assim como os que criavam os filhos de outros. Mas, o conceito de adoção tem passado por alterações, seja no âmbito da lei, seja no imaginário popular (Brodzinsky, Lang \& Smith, 1995; Brodzinsky, Smith \& Brodzinsky, 1998).

Weber (2003) ao fazer o percurso histórico das definições jurídicas de adoção, mostra que no Brasil foi longo o caminho até se chegar às formulações presentes no Estatuto da Criança e do Adolescente (ECA, 1990), que não distinguem estado civil, classe social ou preferência sexual do adotante. Antes do ECA, para se tornar pai adotivo o interessado devia, dentre outras coisas: ter mais de 30 anos, estar casado por mais de cinco, não ter filhos ou possuir atestado de esterilidade de um dos cônjuges, o que dificultava a adoção (Costa, 2005).

A legislação brasileira fortalecia o preconceito ao abordar a adoção como ato civil pelo qual alguém estabelece, em geral com um estranho, um vínculo fictício de paternidade. Como a lei ratificava o estigma da paternidade adotiva como inferior à biológica, os casais só recorriam à adoção depois de esgotadas todas as possibilidades de terem um filho de sangue (Weber, 2003; Granato, 2003).

Hoje, as novas tecnologias de fertilização, como inseminação artificial, fecundação in vitro e aluguel de barriga, têm aumentado as possibilidades do filho consangüíneo e a adoção continua sendo buscada, prioritariamente, por motivos de infertilidade (Weber, 2003; Mariano, 2004). Weber (2003), em pesquisa com famílias de diferentes regiões do Brasil, relata que o principal motivo das adoções realizadas ainda é a necessidade de preencher uma carência dos pais causada pela infertilidade, além da sutil preferência por meninas $(56,6 \%)$, da predominância de adoção de crianças brancas $(70,5 \%)$, com até três meses de idade $(71,4 \%)$.
Santos (1988) chama atenção para a diferença no início da paternidade se adotiva ou biológica. $\mathrm{O}$ pai adotivo não tem que aguardar para romper a fusão entre o filho e a mãe (não há gestação nem amamentação), não está sujeito à fantasia de que o filho pode não ser seu e pode estar mais desejoso de ser pai, já que busca ativamente essa paternidade. Por outro lado, eles podem estar mais sujeitos ao stress na transição para parentalidade do que os biológicos, visto que essa é mais abrupta e sem tanta preparação (Levy-Shiff \& Har-Even, 1991).

Assim, o cenário da adoção parece ser muito rico para a investigação, visto que nesta situação pai e mãe parecem estar 'em pé de igualdade' quanto aos cuidados com a criança. A situação de crise causada pela reconfiguração da dinâmica familiar com a chegada do bebê adotado é um momento privilegiado para apreensão do processo de desenvolvimento de homens que estão se tornando pais pela primeira vez.

Outro aspecto a ser considerado é trazido por Prynn (2001) ao relatar que, na Inglaterra e em outros países, a literatura sobre adoção concentra-se mais na criança do que nos pais adotivos. Logo, tornam-se necessárias investigações que dêem voz a esses pais, que apreendam suas experiências e possam dar suporte a esse tipo de parentalidade.

Desse modo, com o intuito de contribuir com a área e frente à escassez de trabalhos que enfoquem o processo das paternidades adotivas, objetivou-se investigar tal processo sob a ótica do adotante e quais as significações de paternidade que emergem nesse momento.

\section{Método}

A perspectiva teórico-metodológica da Rede de Significações (Rossetti-Ferreira, Amorim, Silva \& Carvalho, 2004), embasou a construção e a análise do corpus dessa pesquisa; ela busca compreender a complexidade do desenvolvimento humano em seu caráter semiótico, discursivo e dialógico. Seus estudos focalizam os processos de construção dos significados e sentidos, ou seja, pesquisas que buscam o ato, a ação de significar (significa-ação) nas interações dos diferentes protagonistas envolvidos (Bruner, 1997). Assim, os comportamentos individuais e os sentidos possíveis de serem construídos de paternidade se dão através de processos dialógicos, 


\section{Raylla Pereira de Andrade}

favorecidos e delimitados pela ação do outro (o filho, a esposa, outros interlocutores) e por elementos físicos, sociais, econômicos e ideológicos.

Participaram deste estudo dois homens casados que passavam pelo processo de adoção de seu primeiro filho, sendo contatados através do Grupo de Apoio à Adoção do qual faziam parte; são pais de camada média, casados com mulheres inseridas no mercado de trabalho, impossibilitados (pela infertilidade da esposa) de gerar um filho biológico e realizaram uma adoção legal de recém-nascido. $\mathrm{O}$ Quadro 1 apresenta uma caracterização dos pais participantes, de suas esposas e crianças.

O estudo utilizou seis entrevistas realizadas através de consentimento informado, recebeu autorização dos participantes para que fossem gravadas em áudio,

Quadro 1: Caracterização dos dois pais participantes do estudo, de suas esposas e crianças

\begin{tabular}{|c|c|c|c|c|}
\hline & \multicolumn{2}{|c|}{ casal 1 (Antônio e Kátia) } & \multicolumn{2}{|c|}{ casal 2 (Márcio e Cristina) } \\
\hline & pai & mãe & pai & mãe \\
\hline $\begin{array}{l}\text { Idade dos pais na primeira } \\
\text { entrevista/na última } \\
\text { entrevista }\end{array}$ & 29 anos/ 30 anos & 30 anos/31 anos & 45 anos/ 46 anos & 42 anos/ 43 anos \\
\hline Escolaridade dos pais & $\begin{array}{c}2^{\circ} \text { grau completo }+ \\
\text { curso técnico em } \\
\text { mecânica }\end{array}$ & \begin{tabular}{|l|} 
superior completo \\
(bióloga)
\end{tabular} & $\begin{array}{l}\text { superior completo } \\
\text { (contábeis) }\end{array}$ & $\begin{array}{l}\text { superior completo } \\
\text { (letras) }\end{array}$ \\
\hline Profissão & autônomo & profa. de ciências & $\begin{array}{l}\text { funcionário } \\
\text { banco }\end{array}$ & profa. de português \\
\hline Cor da pele & pardo & branca & branco & branca \\
\hline Religião & $\begin{array}{l}\text { católico } \\
\text { freqüenta) }\end{array}$ & \begin{tabular}{|l|l|} 
católica (pouco \\
freqüenta)
\end{tabular} & $\begin{array}{l}\text { católico } \\
\text { freqüenta) }\end{array}$ & \begin{tabular}{|ll} 
católica (pouco \\
freqüenta)
\end{tabular} \\
\hline \begin{tabular}{|l|} 
Tempo de casados na \\
primeira entrevista
\end{tabular} & \multicolumn{2}{|l|}{6 anos } & \multicolumn{2}{|l|}{12 anos } \\
\hline Nível sócio-econômico & \multicolumn{2}{|l|}{ camada média } & \multicolumn{2}{|l|}{ camada média } \\
\hline Cidade onde residem & \multicolumn{2}{|c|}{ pequena cidade do interior paulista } & \multicolumn{2}{|c|}{ pequena cidade do interior paulista } \\
\hline $\begin{array}{l}\text { Tempo de espera desde a } \\
\text { primeira ida ao fórum }\end{array}$ & \multicolumn{2}{|c|}{$\begin{array}{l}2 \text { anos (conclusão do processo legal na } \\
3^{2} \text { entrev.) }\end{array}$} & \multicolumn{2}{|c|}{$\begin{array}{l}2 \text { anos (conclusão do processo legal na } \\
2^{2} \text { entrev.) }\end{array}$} \\
\hline Motivação para adoção & \multicolumn{2}{|c|}{ infertilidade (após tratamentos) } & \multicolumn{2}{|c|}{ infertilidade (após tratamentos) } \\
\hline \begin{tabular}{|l|} 
Idade da criança adotada na \\
$1^{\text {a }}$ entrevista
\end{tabular} & \multicolumn{2}{|c|}{7 meses (adotada com 18 dias) } & \multicolumn{2}{|c|}{4 meses (adotado com 13 dias) } \\
\hline $\begin{array}{l}\text { Sexo, cor e nome fictício da } \\
\text { criança adotada }\end{array}$ & \multicolumn{2}{|c|}{ feminino/ branca/ Gisela ${ }^{1}$} & \multicolumn{2}{|c|}{ masculino/ branco/ João ${ }^{1}$} \\
\hline
\end{tabular}

'Nomes fictícios

transcritas, armazenadas num banco de dados do grupo de pesquisa e analisadas por outros pesquisadores. O material empírico compõe-se de três entrevistas domiciliares com o casal 1 , sendo a primeira individual com o pai e duas com o casal, e três com o casal $2^{5}$, todas conjuntas e realizadas ao longo de um ano e meio. As entrevistas semi-estruturadas buscavam conhecer como aqueles homens e mulheres, conforme passavam pela experiência de adotarem um filho, construíam significações de paternidade e maternidade.

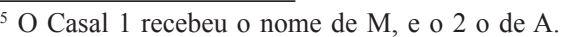

A pesquisa se constitui em estudo de caso, o que envolve análise intensiva de um número reduzido de casos, focalizando o processo e não o resultado, (Fachin, 2003; Fonseca, 1999).

A análise focalizou as significações sobre paternidade que emergiram na conversação com os pais ou casal, durante o tempo de acompanhamento. $\mathrm{O}$ tratamento das entrevistas incluiu: (1) leituras exaustivas, para identificar os assuntos abordados mantendo a cronologia da narrativa; (2) levantamento temático de cada entrevista visando sua caracterização geral; (3) levantamento dos interlocutores em cada 
tema, buscando apreender as diferentes vozes presentes no discurso (Spink, 1999); (4) agrupamento em eixos de significação agregando significações relevantes para a compreensão das paternidades investigadas, sendo eles: a) paternidade e família; b) paternidade e conjugalidade; c) paternidade e adoção e; d) o ser pai.

\section{Resultados e discussão}

\section{a) Paternidade e família}

Em relação às significações do que é uma família, M e A trazem em seus relatos sentidos associados à concepção de família nuclear, aquela composta pelo casal (unido pelo matrimônio) e os filhos, os quais devem vir para completar os vazios da vida a dois, como decorrência "natural" do casamento.

"Nesse trilhar todo, numa convivência assim, a tendência é ter um filho. Por quê? Ahhh, família, né? Tipo assim: pai, mãe e filho. Tem que ter uma pessoa que continue o que a gente tá fazendo aqui". (A, $1^{a}$ entrev.)

Diante da pergunta, como é que está sendo ser pai? A resposta é:

(...) é muito bom. Na verdade, eu que vim de uma família grande, nós somos uma família muito unida. Então, é assim a gente tem aquela questão da família, como que a família...é $\underline{a}$ base, a família (...) E isso, realmente, eu acho que faz falta, né, pra gente essa continuação". (M, $1^{a}$ entrev.)

Os pais M e A são provenientes de famílias grandes e vêem o filho como continuidade deles no mundo, no entanto, divergem quanto ao valor atribuído à educação recebida de seus pais. Enquanto $M$ relata buscar seguir seus padrões familiares na educação do filho, A diz querer romper com seu modelo de infância, especialmente por seu pai ser alcoolista e ausente.

"Se você tirar por base da minha família, não, não é a educação que eu quero dar pra minha filha”. (A, 2 ${ }^{a}$ entrev.)

Alguns autores (Badinter, 1985; Sheehy, 1997; Lamb, 1997) defendem que os significados da paternidade são fortemente influenciados pelas experiências dos homens com seus próprios pais. Badinter
(1985) aponta o desejo dos "novos pais" de romperem com o modelo em que foram criados, já que consideram o comportamento de seus pais "frio e distante", como no caso de A.

Percebe-se ainda que as duas paternidades estudadas são atravessadas pelos discursos de uma camada média emergente que escolhe o momento mais adequado para conceber um filho. Nesse sentido, ele é pensado a partir do momento em que o casal alcança estabilidade financeira e emocional, o que no senso comum se conhece como "uma família estruturada". $\mathrm{Na}$ espera por essa estabilidade e estruturação, a vinda do filho pode ser postergada para uma idade mais avançada, como observado, principalmente, no caso de $\mathrm{M}$.

\section{b) Paternidade e conjugalidade}

Olhando para essas paternidades de forma relacional, nota-se que há momentos de negociação entre os pais e suas esposas, destacando-se as relativas às funções de provedor do lar e cuidador dos filhos.

\begin{abstract}
"Eu antes falava: 'Th, K, ela (a filha) fez cocô, né?' Agora eu num posso falar. Eu tenho que pegar e trocar, porque ela fala: 'Então troca',". (A, $2^{a}$ entrev.)

"Eu sempre fui criada em família. Então, isso eu sempre cobrei dele (A) (...) Ou é um pai presente, um marido presente, ou então, pra viver sozinha, eu vou viver sozinha...com o que eu ganho e acabou, né? (A diz "é") Só pra pôr dinheiro em casa não tem necessidade". (K, $2^{a}$ entrev.).
\end{abstract}

Ao instigar A a cuidar da filha, $\mathrm{K}$ faz com que ele ressignifique seu papel de pai e altere suas atitudes (passa a trocar fralda). Essa transição de "velhos" para "novos" comportamentos é reveladora da emergência de significados e demonstra a importância dos posicionamentos delegados aos outros, assumidos ou negados no processo de construção de significados. Nos dois trechos citados, A é posicionado por sua esposa como um pai presente e cuidador, o que contribui para que se constitua com tais características. Assim, há fluidez e dialética dos jogos de posicionamentos na relação do casal (Rossetti-Ferreira \& cols., 2004). 
Entretanto, em momentos anteriores, $\mathrm{K}$ afirmou que a preocupação do homem geralmente é trabalhar para sustentar a casa e a família, o que é endossado por $\mathrm{A}$, que várias vezes ressaltou a importância de seu trabalho.

\begin{abstract}
"A primeira coisa que a gente tem que se preocupar é como vai cuidar dela (filha). Como a K também trabalha, dá uma parte, dá uma ajuda pra gente, pra mim, financeiramente dentro de casa. Eu falei pra ela: 'É complicado que cê tem uma carga de horas-aula. Ela falou: 'Ah, eu vou diminuir.' 'Então, tudo bem. Cê trabalha menos, eu trabalho mais". (A, 1'aentrev.)
\end{abstract}

Ao mesmo tempo, A é significado como "ajudante" nos cuidados infantis. Ao ser questionado se há diferença entre o papel de pai e de mãe, ele afirma:

“ A carga da mãe é muito maior que a do pai. É cuidar, é tratar, é saber cuidar (...) da educação nem tanto porque o pai ajuda bastante, mas ela tem uma carga maior." (A, $2^{a}$ entrev.)

Esse posicionamento de ajudante nos cuidados infantis é assumido por A que se orgulha dos cuidados que ele tem com a filha como, às vezes, preparar o banho ou a comida, brincar, trocar fraldas. Já $M$, não refere momentos de negociação tão explícitos, mas também é significado como ajudante da mãe nos cuidados infantis, juntamente com outros (empregada, sogra, vizinha.)

Diante da questão -E como o $M$ é como pai?

Ah, o M baba, né? A única coisa que ele é, assim, é desajeitado pra pegar uma criança. Mas se eu peço pra ele me ajudar, nossa, o maior carinho, pro que é preciso, e num tem o que falar (...) Mas no dia-a-dia aqui sou eu. Eu tenho que ver o que é melhor o que falta, o que não falta”. (C, $1^{a}$ entrev.)

Além de ser significado e posicionado como ajudante, $\mathrm{M}$ também se descreve (diante do filho, da esposa e da entrevistadora) como um pai "desajeitado", assumindo um discurso de que pai é despreparado para os cuidados infantis e não sabe paternar "corretamente".

"A chupeta você quer? (falando com o filho). Papai desajeitado, né? (M, $1^{a}$ entrev.)
Em diálogo com esse discurso da incompetência masculina para cuidar dos filhos, Badinter (1993) afirma que o cuidado não está relacionado com sexo ou com fisiologia, dependendo mais da infância de cada um e de circunstâncias externas, como a cultura e a relação marital. No imaginário popular ainda é forte a idéia de que alguns cuidados infantis (como manipulação do corpo) são "negócio de mulher" (Bustamante \& Trad, 2005). Os achados de pesquisa de Braz, Dessen e Silva (2005) mostram que a maioria dos cônjuges entrevistados ( $86 \%$ de 14 famílias) acredita que o relacionamento do casal interfere direta e indiretamente nas relações parentais.

\section{c) Paternidade e adoção}

$\mathrm{M}$ e A trazem em seus relatos diferentes situações e sentidos relacionados à paternidade, específicos desse contexto de parentalidade adotiva. Assim, esse eixo de significação foi dividido em três partes que tiveram maior relevância, a partir dos relatos.

1) Adoção legal e revelação: A e M afirmam que a opção pela adoção legal foi para evitar o risco de um dia a genitora, a qual consideram uma heroína por não ter abortado e dado a eles a oportunidade de serem pais, retornar e levar a criança embora. Ambos relatam essa relação ambígua com a genitora, que ao mesmo tempo é enaltecida, valorizada e temida. A paternidade deles parece ameaçada por essa figura. Assim, eles conhecem pouco da história dos pais biológicos de seus filhos, não buscam esse conhecimento e parecem negar esse passado, embora achem importante a criança conhecer sua história. Entretanto, tanto $\mathrm{M}$ quanto A demonstram dúvidas em relação a como fazer a revelação.

"O pouco que nós sabemos, eu acho que nós vamos contar a história e, se um dia, realmente, ele quiser conhecer eu acho que é difícil a gente inibir. Não é verdade? (...) Eu acho que até a criança se sente mais forte, a gente contando, tá certo? Até para o bem da criança é importante". (M, $1^{a}$ entrev.)

"Eu tenho dúvida assim... em como contar pra ele, sabe? (...) Mas nós queremos contar sim. Não queremos esconder". (M, $2^{a}$ entrev.)

“A gente se acostumou a ter ela (filha) (...) Então, vai te apagando aquilo... Nossa, uma 
criança dentro de casa? Uma terceira pessoa... No começo tinha isso, agora não existe mais. Agora é família, né?" ( A, $2^{a}$ entrev.)

Evidenciando os sentido associados à revelação e partilhados por A de sua esposa, apresentamos uma fala de $\mathrm{K}$ que traduz em grande parte o que foi exposto pelo casal na segunda entrevista (quando $\mathrm{G}$ estava com um ano):

"Eu não sei se vô conseguir falar. Não por medo da reação, ou por falta de coragem, mas sim pelo sentimento. Eu já não sinto mais ela como adotiva. É adotiva, realmente, eu adotei ela como minha filha. Mas é...complicado. Hoje eu acho mais dificil, isso." (K, $2^{a}$ entrev.)

Observa-se que com o passar do tempo e a convivência com a criança, a questão da revelação se impõe aos pais como algo necessário, porém, difícil. Na pesquisa de Weber (2003), a maioria dos adotados $(67,7 \%)$ acreditava que ter o conhecimento da adoção é fundamental e apenas $3,8 \%$ dos pais adotivos disseram não ter revelado a verdade e não pretender fazê-lo. No entanto, embora, aparentemente, todos saibam que a revelação é necessária e que a omissão pode gerar problemas emocionais ao adotado, muitos pais têm dificuldade de falar do passado da criança e temem a revelação (Turcatto, 2002; Brodzinsky, Smith \& Brodzinsky, 1998; Brauer, 1993).

Tal dificuldade parece estar presente no caso de $\mathrm{A}$, que não consegue mais falar do passado da filha à medida que esta vai crescendo e compreendendo mais o que se conversa perto dela. Como G chegou na casa com 18 dias, os pais é que decidirão se vão revelar a ela sua história de abrigamento e adoção.

2) O estranhamento da paternidade adotiva no meio social: M e A têm experiências um pouco diferentes em relação a esse tópico, pois enquanto $M$ relata que não sentiu reação negativa das pessoas frente à adoção, A afirma que sentiu. Para ele, freqüentar o grupo de apoio à adoção e conversar com quem já passou pela experiência de adotar foi fundamental para a superação de tais preconceitos.

"Porque, na verdade, às vezes, a gente ficava com aquele receio mesmo que iria ter muita restrição, né? Mas não. Eu acho que as pesso- as até admiraram o gesto que nós tivemos (...) mas num teve nada, assim, restritivo, não. Realmente, a aceitação perante os colegas, perante a sociedade, foi muito boa, acho (...) até no momento. E mesmo que tenha, nós estamos preparados pra aceitar, pra conviver com isso." $M, 1^{a}$ entrev.)

É importante o grupo de apoio, porque ele une casais e isso é importante, porque um filho dentro de casa muitas pessoas pensam que é uma pessoa estranha que entrou na sua familia e não! A Minha filha é Minha filha, é neta da minha sogra, tá muito bem assim.. adotada mesmo! Mas de coração mesmo!" (A, $1^{a}$ entrev.).

A diz que a criança adotada não é uma "estranha" e usa o pronome possessivo "minha" por duas vezes para enfatizar que é sua filha, filha do coração. Sente-se pai de G, assume que ela é adotada, mas fala da adoção afetiva que foi feita paralelamente à legal, por ele e membros da família. Essa não parece ser uma paternidade hesitante. Como apresentado na introdução, a forma preconceituosa, citada por A, de se referir à criança adotada como "estranha", tem sua origem nas próprias leis que regulamentaram a adoção antes do surgimento do ECA. A dialoga com um discurso construído socialmente e que vem sendo alterado no decorrer da história da adoção no Brasil.

3) Fantasias e expectativas sobre a criança a ser adotada: embora $\mathrm{Me}$ A tenham sido ouvidos pela equipe interdisciplinar do Fórum a respeito de suas preferências pelo filho vindouro, tendo pensado em questões como cor, sexo, idade, condições de saúde da criança (escolhas que não ocorrem num processo de filiação biológica), o inesperado parece que continua a rondar-lhes. Quanto tempo levará até eles conhecerem a(o) futura(o) filha(o)? Como será a criança? E se não houver empatia no primeiro encontro? E se a criança não os reconhecer como pais futuramente? E se ela após a adoção, manifestar alguma doença? E se a mãe biológica reconhecer seu filho quando mais velho?

Essas são fantasias e expectativas presentes nas redes de significações de $\mathrm{M}$ e A, em parte alimentadas por discursos sociais que apontam casos de adoção de crianças mal-sucedidos, o que pode gerar expectativas negativas nos pretendentes à ado- 
ção. No caso de $\mathrm{A}$ isso é notável, enquanto $\mathrm{M}$ se mostra mais tranqüilo em relação a essas questões.

"Eu acho que com relação a trazer (influências genéticas) com o tempo muda. Eu acho que vai adaptando a educação que os pais, os valores que os pais vão passando. Eu não tenho essa preocupação de ter problemas futuros com ele (filho), de relacionamento (...) Eu acho que vai da convivência, do que nós passarmos pra ele, né?" (M, $3^{a}$ entrev.)

“Eu não esperava ter uma menina tão linda assim. Eu imaginava uma criança, ahnn...com pequenos problemas de saúde, porque a gente sempre ouve (...) agitada. Eu tava me prevenindo. É uma criança super dócil. Acorda uma vez por noite. Então, isso ajuda muito" ( $A, 1^{a}$ entrev.)

M afirma que, apesar do filho trazer influências genéticas dos genitores, o mais importante na constituição da personalidade da criança é a convivência com os pais e a educação recebida destes. Com isso, ele confere a si um papel como pai muito importante na criação de $J$.

Já A demonstra receios em relação à aparência física, à saúde da criança e possíveis seqüelas de sua história pregressa, evidenciando idéias preconcebidas a respeito de crianças em adoção. Ele também explicita a construção de sua paternidade na relação com a filha, mesmo que recém-nascida e, aparentemente, pouco ativa relatando características físicas (linda, saudável) e comportamentais (dócil, dorme bem) o ajudam muito na aceitação dela como filha.

"A gente esperava que não fosse tão bom quanto é a saúde dela (filha), né? Que, quer queira ou não, não menosprezando, mas é uma caixinha de surpresa uma adoção (...) Porque você não sabe, você tem alguns critérios, que a gente pede, você tem direito, né? Vamos se dizer assim, entre aspas. Mas, é uma caixinha de surpresa. Uma criança é uma caixinha de surpresa. De repente você abre, tem um monte de coisinha, é um enjoozinho, uma dorzinha" (A, $3^{a}$ entrev.)

A argumenta que, mesmo com a possibilidade de definir critérios sobre a criança desejada, ainda continua a existir o risco de que esta não corresponda às expectativas e os surpreenda. Para ele, no caso de um filho biológico, "você tem algumas referências genéticas", enquanto, uma adoção "é uma coisa um pouco escura, oculta". Por tudo isso e pelos comentários que ele ouve a respeito de crianças adotadas é que este se mostra surpreso com todas as qualidades de $\mathrm{G}$.

\section{4) $\mathrm{O}$ ser pai,}

Ao longo dos três momentos de entrevista com $\mathrm{M}$ e A eles afirmaram estarem muito felizes com a chegada do filho e descreveram o papel de pai como muito bom e de valor imensurável. Diante da questão, como é que é você com ele? Você com o J.? as respostas foram:

É uma sensação gostosa (...) é algo diferente de dois anos atrás, que a gente chegava era mais tranqüilo, dava pra assistir jornal, ler jornal, revista, que isso já não dá mais. Mas é uma mudança, assim, que ele (filho) vem, a gente brinca, roda no chão, essas coisas, sabe? (...) esse lado, afetuoso da criança, muda, eu acho que não tem o que pague isso". ( $M, 3^{a}$ entrev.)

"Ser pai é, você tem alguns atributos nos seus deveres e que são diferentes no cotidiano. Por exemplo, você se preocupa constantemente onde ela tá, o que tá fazendo, o que tem que fazê, mas num tem coisa mais linda no mundo (...) num tem dinheiro que se pague pela alegria que dá”. (A, $3^{a}$ entrev.)

"Ah, ser pai é muito gostoso! (Rindo) (...) Porque filho não é simplesmente um ser humano que você põe em casa, você troca a fralda, você cuida, você dá um brinquedinho e tudo bem. Não! Merece, precisa de uma atenção completamente (enfatiza) diferente (...) Primeira atenção é pra menina! Muda bastante a vida... do casal." (A, $1^{a}$ entrev.)

Pelas falas de $\mathrm{M}$ e A nota-se o relato de mudanças ocorridas com a chegada da criança, isto é, a reconfiguração das Redes de Significações e a alteração dos papéis assumidos por eles (e delegados aos outros) acontecendo na interação com o novo elemento na família (Rossetti-Ferreira \& cols., 2004). Além disso, os dois pais afirmam que o filho tem sido prioridade, inclusive, em relação às esposas. Essa predominância do papel de pai ou de mãe sobre a 
relação entre os cônjuges é definida por Salém (1989), como uma situação anômala nos "casais igualitários", já que os filhos não deveriam vir para dar sentido à vida conjugal.

Para falar de sua paternidade, mais especificamente relacionando-a ao contexto adotivo, A traz ainda o sentido de desafio que foi assumir uma paternidade diferente da inicialmente imaginada (biológica), colocando a adoção como uma barreira a ser atravessada.

"Como pai, eu me sinto uma pessoa realizada, primeiro porque eu, particularmente, né? Atravessei uma barreira, que não é todo mundo que quer atravessar, tipo assim, entrar numa adoção. Eu me vejo feliz pela situação porque eu me dou muito bem com a minha filha." (A $1^{a}$ entrev.)

Vale também ressaltar que A e M mantêm como padrão falar de alguns pontos negativos (ex. preocupação financeira, aumento de responsabilidade, correria no cotidiano) e finalizar enfatizando os pontos positivos. A alta freqüência dessa postura levou a hipotetizar que talvez esse discurso otimista se configure assim devido ao fato de ser direcionado a uma psicóloga e pesquisadora. Nesse sentido, Fonseca (1999) alerta para a possibilidade de o entrevistado ajustar sua narrativa às expectativas do pesquisador e assumir um discurso que considera adequado, excluindo outros tantos possíveis dentro de uma realidade social multifacetada.

Entretanto, outros autores (Badinter, 1993, Sheehy, 1997) argumentam que é comum os pais mais participativos se dizerem felizes com a vivência de paternidade e mostrarem suas emoções na relação com o filho. Na pesquisa de Trindade e Menandro (2002) com 8 pais adolescentes também se verificou que a maioria relatava satisfação com a condição de pai, a despeito do aumento de responsabilidade.

M e A acreditam que o papel do pai envolve, além da função de provedor, a de educar, transmitir valores da família, ser um orientador mostrando os "caminhos certos" para o filho e, ainda, ser amigo. Os trechos seguintes demonstram as expectativas que eles têm em relação ao próprio desempenho e ao mesmo tempo o receio de não "cumprir" com esse papel adequadamente. Eles demonstram o quão de- safiador é para o homem e, por vezes, angustiante, tornar-se pai.

“(...) O futuro de encaminhar ele (filho) na vida, né? Seria nesses termos, assim. A questão de estudos... Acho que passar os nossos valores pra ele (...) valores de família, valores de religião, acho que isso é importante. De cidadania (...) valores de respeito às pessoas (...) Isso que eu quero passar, como pai, passar pra ele (...) E de humildade, essas coisas, assim, de...

As respostas à questão: $\mathrm{O}$ que você acha que ia ser legal entre você e o J? (...)

M: Amizade, respeito mútuo, aprendizagem, né?" (M, 2aentrev.)

"Eu quero, eu tento (enfatiza) ser o melhor pai do mundo, nunca vou conseguir esse mérito, essa medalha, porque eu acho que num existe, por mais que eu tente dá educação, mostrar pra ela os caminhos certos, acho que eu vou falhar em alguma coisa, porque ninguém é perfeito". (A, $3^{a}$ entrev.)

\section{Considerações finais}

Ao considerar que o processo de construção de uma paternidade (adotiva ou não) é atravessado por vários discursos e possibilidades próprios do contexto sócio-histórico de uma época, investigaram-se as significações de paternidade emergentes nas entrevistas com os dois pais adotantes, sempre considerando o contexto social do início do século XXI.

Esse cuidado de contextualizar o momento histórico e os discursos predominantes sobre paternidade e adoção está em consonância com o argumento da literatura de gênero a respeito do masculino e feminino serem categorias inscritas no social e não um produto da natureza. Por isso, não se pode falar de uma essência masculina, de caráter abstrato e universal, mas sim de um homem (e de um pai) multifacetado, situado temporal e relacionalmente.

Percebeu-se, por exemplo, a influência de um discurso comum da camada média sobre a construção dessas duas paternidades investigadas, que se refere à busca de estabilidade financeira e emocional do casal antes de receber um filho, o qual deve vir para completar a família, ou, em outras palavras, cons- 
tituir a família nuclear tida como modelo para M e A (Salém, 1989).

O presente estudo ratifica a literatura da área em relação à assincronia entre o discurso e a prática da paternidade (Atkinson \& Blackwelder, 1993; Gomes \& Resende, 2004; Jablonski, 1998; LaRossa, 1988; Quadros, 1996; Salém, 1989; Unbenhaum, 2000). Tanto M quanto A têm um discurso igualitário, vivem com mulheres inseridas no mercado de trabalho e se dizem envolvidos nos cuidados com o filho recém-nascido, mas no dia-a-dia as esposas ainda são as principais responsáveis pelos cuidados infantis e tarefas domésticas. Esses pais assumem o papel de "ajudantes" nos cuidados com o filho e ainda se preocupam, prioritariamente, com a situação financeira da família.

Entretanto, esses posicionamentos, apesar de predominantes, não são estáticos, sendo permanentemente negociados na relação conjugal e no diálogo com outros discursos e práticas sociais. Assim, não se pode tentar encaixar esses pais dentro de modelos cristalizados como "pai tradicional" e "novo pai”, já que as influências na vivência de paternidade são múltiplas e tais modelos podem conviver e se alternar na experiência de um mesmo pai. Nos casos de $\mathrm{M}$ e A fica evidente que o modelo tradicional de paternidade, no qual o papel do pai é o de chefe e provedor da família, convive com um outro modelo, em que o pai também é cuidador e participa do cotidiano do filho.

Os relatos apontam para uma transformação do papel tradicional de pai em direção a uma "nova paternidade", mas mostra que essa vem ocorrendo de forma lenta e gradativa, já que "a mudança de hábitos não acompanha o ritmo da transformação de valores" (Gomes \& Resende, 2004, p.119). Percebese que eles valorizam a troca de carinho e afeto com o filho, os cuidados físicos, a educação (transmissão de valores), mas a significação de paternidade mais forte ainda é a de pai como provedor, sendo essa a atitude mais presente no cotidiano da família (Trindade \& Menandro, 2002).

Em relação a esses homens serem pais por adoção, percebe-se que aparecem diferentes situações e sentidos de paternidade específicos do contexto de parentalidade adotiva, como a opção pela adoção legal por medo dos genitores reaparecerem; o receio de influências genéticas desconhecidas no comportamento de seus filhos; preconceitos dos outros frente à adoção feita por eles; a busca da adoção pela infertilidade do casal; vontade de esquecer o passado da criança e dúvidas/dificuldades no que tange à revelação; importância do grupo de apoio à adoção como suporte nesse processo de adaptação ao filho adotado; possibilidade de escolha da criança desejada no processo judicial; tentativa de reprodução do modelo biológico ao adotarem um recém-nascido.

Os casos de adoção investigados nesse estudo apresentam dois fatores comuns e constantemente presentes na literatura: $1^{\circ}$.) o principal motivo para a decisão de adotar ser a necessidade de preencher a falta de um filho (infertilidade) e, $2^{\circ}$.) as características da criança desejada (recém-nascido) serem as mais comumente encontradas tanto nos cadastros de adoção, quanto nas adoções realizadas (Mariano, 2004; Weber, 2003). Esse é um indicador de que os casais procuram reproduzir o modelo da família biológica adotando bebês e privilegiando o perfil correspondente ao padrão familiar socialmente mais aceito e valorizado (Pereira \& Santos, 1999). As paternidades de M e A estão atravessadas por essa significação.

Assim, o material desse estudo pode lançar idéias para novos estudos sobre o tema. A realização de outras pesquisas sobre paternidade se faz necessária, já que essa tem passado por profundas transformações. Concluindo, a pesquisa evidencia a impossibilidade de se falar de uma única construção de paternidade, como se existisse uma forma universal de vivenciar essa experiência. Fala-se sim de paternidades múltiplas, multifacetadas e em constante movimento.

\section{Referências}

Áries, P. (1981). História social da criança e da família. Rio de Janeiro: Editora LTC.

Arilha, M; Medrado, B. \& Ridenti, S. G. U. (1998). Homens e masculinidades - outras palavras. São Paulo: ECOS.

Atkinson, M. P. \& Blackwelder, S. P. (1993). Fathering in the 20th Century. Journal of Marriage and the Family, 55, 975-986. 
Badinter, E. (1985). Um amor conquistado: o mito do amor materno. Rio de Janeiro: Nova Fronteira.

Badinter, E. (1993). XY sobre a identidade masculina. Rio de Janeiro: Nova Fronteira.

Brauer, J. F. (1993). Adoção de crianças: aspectos psicológicos. Pediatria Moderna, v. 29, n.7, 1018-1020.

Braz, M. P.; Dessen, M. A. \& Silva, N. L. P. (2005). Relações conjugais e parentais: uma comparação entre famílias de classes sociais baixa e média. Psicologia: Reflexão e Crítica, v.18, n.2, 151-161.

Brodzinsky, D. M.; Lang, R. \& Smith, D. W. (1995). Parenting Adopted Children. In M.H. Bornstein (Ed.), Handbook of parenting (pp.209232). New Jersey: Lawrence Erlbaum Associates Publishers.

Brodzinsky, D. M.; Smith, D. W. \& Brodzinsky, A. B. (1998). Children's Adjustment to Adoption: developmental and clinical issues. Thousand Oaks: Sage.

Bruner, J. (1997). Atos de significação. Porto Alegre: Artes Médicas.

Bustamante, V. \& Trad, L. A. B. (2005). Participação paterna no cuidado de crianças pequenas: um estudo etnográfico com famílias de camadas populares. Cadernos de Saúde Pública, v. 21, n.6, 1865-1875.

Costa, N. R. A. (2005). Construção de sentidos relacionados à maternidade e à paternidade em uma familia adotiva. Tese de doutorado, FFCL, Universidade de São Paulo, Ribeirão Preto.

Estatuto da criança e do adolescente.(1990) Brasília: Ministério da Saúde/Projeto Minha Gente.

Fachin, O. (2003)._Fundamentos de metodologia. São Paulo: Saraiva.

Fonseca, C. (1995). Caminhos da adoção. São Paulo: Cortez.

Fonseca, C. (1999). Quando cada caso não é um caso. Pesquisa etnográfica e educação. Revista Brasileira de Educação, 10, 58-78.
Gomes, A. J. S. \& Resende, V. R. (2004). O pai presente: O desvelar da paternidade em uma família contemporânea. Psicologia Teoria e Pesqui$s a, v .20, \mathrm{n} .2,119-125$.

Granato, E. F. R. (2003). Adoção: doutrina e prática. Curitiba: Juruá.

Hennigen, I. \& Guareschi, N. (2002). A paternidade na contemporaneidade: um estudo de mídia sob a perspectiva dos Estudos Culturais. Psicologia \& Sociedade, v.14, n.1, 44-68.

Jablonski, B. (1998). Até que a vida nos separe - a crise do casamento contemporâneo. Rio de Janeiro: Agir.

Lamb, M. E. (1997). The role of the father in child development. New York: John Wiley.

LaRossa, R. (1988). Fatherhood and social change. Family Relations, v.37, n.4, 451-457.

Levy-Shiff, I. G. \& Har-Even, D. (1991). Transitions to Parenthood in Adoptive Families. Developmental Psychology, 27, 131-140.

Lewis, C. \& Dessen, M. A. (1999). O pai no contexto familiar. Psicologia: Teoria e Pesquisa, v. 15, n.1, 09-16.

Mariano, F. N. (2004). O cenário jurídico: a análise de processos de adoção no município de Ribeirão Preto (1991-2000). Dissertação de Mestrado, Faculdade de Filosofia, Ciências e Letras, Universidade de São Paulo, Ribeirão Preto.

Pereira, J. M. F. \& Santos, M. A. (1999). O Enfoque psicológico da adoção: Revisão da literatura. Em R.C. Labate (Org.), Caminhando para a assistência integral (pp. 225-246). Ribeirão Preto: Scala.

Prynn, B. (2001) . Family building in adoption. Adoption \& Fostering, v.25, n.1, 33-43.

Quadros, M. T. (1996). Construindo uma nova paternidade? As representações masculinas de pais pertencentes às camadas médias em uma escola alternativa do Recife, PE. Dissertação de Mestrado, Universidade Federal de Pernambuco, Recife. 
Rodrigues, M. M., \& Trindade, Z. A. (1999). Em nome do pai e do filho: relações afetivas e instrumentais. Em P. R. Menandro, Z. A. Trindade \& E. B. Borloti (Orgs.), Pesquisa em Psicologia: recriando métodos (pp. 125-138). Vitória: Universidade Federal do Espírito Santo.

Rossetti-Ferreira, M. C.; Amorim, K. S.; Silva, A. P. S. \& Carvalho, A. M. A. (2004). Rede de Significações e o estudo do desenvolvimento humano. Porto Alegre: Artes Médicas.

Salém, T. (1989). O casal igualitário: princípios e impasses. Revista Brasileira de Ciências Sociais, 9, 24-36.

Santos, N. P. F. (1988). As possibilidades de satisfação na adoção. Psicologia: Teoria e Pesqui$s a, v .4$, n.2, 113-128.

Sheehy, G. (1997). A onda de otimismo. Em G. Sheehy (Org.), Novas Passagens- Um Roteiro para a Vida Inteira (pp. 284-296). Rio de Janeiro: Racco.

Spink, M. J. (1999). Práticas discursivas e produção de sentidos no cotidiano - aproximações teórico e metodológicas. São Paulo: Cortez.

This, B. (1987). O pai: Ato de nascimento. Porto Alegre: Artes Médicas.

Trindade, Z. A. \& Menandro, M. C. S. (2002). Pais adolescentes: vivência e significação. Estudos de Psicologia, v.7, n.1, 15-23.

Turcatto, S. A. (2002). Repensando a maternidade/paternidade pela via da adoção: Um estudo sobre a família adotiva na atualidade. Dissertação de Mestrado, FCL, Universidade Estadual Paulista, Assis.

Unbehaum, S. G. (2000). Experiência masculina da paternidade nos anos 1990: estudo de relações de gênero com homens de camadas médias. Dissertação de Mestrado, FFLCH, Universidade de São Paulo, São Paulo.

Weber, L. N. D. (2003). Pais e filhos por adoção no Brasil: características, expectativas e sentimentos. Curitiba: Juruá.
Este trabalho foi baseado no projeto de Iniciação Científica, intitulado "A Construção da paternidade no processo de adoção do primeiro filho" (FAPESP)

\section{Apoio: FAPESP}

